
Y CONMEMORACIÓN EN CHILE. 1990 AL PRESENTE Voiced objects

\author{
Crossroads and challenges in contexts of memory and commemoration in \\ Chile.1990 to the present
}

\title{
JAVIERA BUSTAMANTE*
}

\section{Fecha de recepción: 4 de septiembre de 2015- Fecha de aprobación: 27 de enero de 2016}

\section{Resumen}

Los ejercicios de comprensión y reflexión de materialidad y recuerdo se preguntan una y otra vez por dónde está la memoria, una interrogante que ha sido contestada básicamente desde la categoría del lugar. En el desafío de comprender las prácticas mnemónicas, nos encontramos con un amplio repertorio de objetos que ha redituado descriptivamente, pero que al mismo tiempo ha sido parcialmente ignorado de los estudios de cultura material y memoria. El siguiente artículo invita a complementar este campo de investigación con una indagación en los objetos, aspirando a situarlos como un tópico de vivo interés para el estudio de las prácticas mnemónicas. El objetivo es describir y reflexionar en torno al papel que juegan (y pueden jugar) los objetos en los procesos de memoria y conmemoración del pasado reciente en Chile, a partir de la información obtenida por tres caminos: a) Entrevistas a donantes de objetos al Museo de la Memoria de Santiago, Chile, a familiares de la AFDD de Paine que conservaban sus objetos y a coordinadores de proyectos de memoria y objetos; b) Realización de Talleres de Química de la Memoria y c) Etnografía de contextos conmemorativos con presencia de objetos de memoria.

Palabras clave: objetos, memoria, recuerdo y conmemoración.

\begin{abstract}
Exercises of comprehension and reflection upon materiality and remembrance, recurrently lead to inquire where memory lay. The latter interrogation has been answered through the perspective of a place. Amidst the challenge of understanding mnemonic practices, we may find an ample repertoire of objects that provide descriptive material. Unfortunately, such a practice has been effectively ignored in studies of material culture and memory. The present article invites to enhance this specific field of research with an assay on objects, a field that might well become of active interest in the study of mnemonic practices. Its objective is to describe and deliberate upon the role that objects play (and could play) in the process of memory and commemoration of the recent past in Chile. To achieve the latter, information has been obtained from three sources: a) Interviews with donors of objects to the "Museo de la Memoria" in Santiago, Chile; with members of Paine AFDD, that preserve these objects; and with coordinators of memory and objects projects; b) Chemistry of Memory workshops; and c) Ethnography of commemorative contexts with the presence of objects of memory.
\end{abstract}

Keywords: objects, memory, remembrance and commemoration.

* Antropóloga Social, Universidad de Chile. Doctora en Gestión de la cultura y el Patrimonio, Universidad de Barcelona. Correo-e: bustamante.javiera@gmail.com 
Reposición del objeto para los estudios de memoria

"Pero todavía una fuente, el detalle de una fachada, el maíz, o el jamón que cuelga del techo de una taberna, un organillo o un tocadiscos. Edison en las sombras de una tienda, la forma curva de una mesa, juguetes, fotos de familia, los fragmentos viajeros de una canción... Esta población extiende sus ramificaciones, penetra toda la red de nuestra vida cotidiana, desciende a los laberintos del hábitat, coloniza en silencio sus profundidades" (Michel De Certeau, 1999)

El siguiente trabajo se inserta en el campo de investigación de prácticas y procesos de memorias y conmemoraciones desarrollados en contextos postconflicto de países de Latinoamérica y Europa. Tras álgidas oleadas de investigaciones en la materia, es posible decir, de manera general, que estos estudios se han desarrollado prioritariamente en torno a la categoría definida como lugares, espacios o territorios de memoria. La pregunta por dónde está la memoria, ha sido contestada básicamente desde la anatomía del lugar, entendiéndolo como territorio que alberga acontecimientos y prácticas mnemónicas, en el sentido de lugar acontecido y de prácticas de recuerdo en un tiempo presente. En este punto, es posible señalar que esta tendencia sería tributaria de una gestión política gubernamental de la memoria que ha antepuesto la construcción de sitios de recuerdo y la recuperación y musealización de sitios históricos con el fin de reivindicar, reparar, homenajear y recordar a las víctimas que murieron o sobrevivieron a su paso por dichos lugares. Esta objetivación de la memoria ha motivado un amplio, diverso e interesante corpus reflexivo en torno a la estrecha relación existente entre memoria, recuerdo, conmemoración y espacios. Desde aquí ha emergido un variado mosaico de exploraciones que, entre otros muchos objetivos, han buscado reflexionar sobre las relaciones entre espacios y comunidades, las resignificaciones y reutilizaciones de los espacios, las dinámicas y soportes simbólicos construidos y reconstruidos y las reinterpretaciones y representaciones dinamizadas por los grupos en dichos espacios, por mencionar solo algunas líneas de investigación. También se visualizan proyectos de recuperación y construcción de archivos, donde el propósito reside en registrar y custodiar el legado material que dispuestos en plataformas digitales y presenciales permiten aproximarnos a "microhistorias", testimonios personales y colectivos, siempre subjetivos.

Tras esta constatación, surgió un profundo interés hacia los objetos y su participación en distintas prácticas y procesos desplegados en los espacios de memoria, necesidad que no emergió simplemente de una sospecha; en la gestión de la memoria y la conmemoración de pasados conflictivos los objetos han tenido una participación fundamental -no siempre valorada-, especialmente en museos que en distintas formas han buscado transmitir y explicar episodios traumáticos. En todos estos casos, como por ejemplo el Museo Judío de Berlín, el Museo del Holocausto en Washington, el Museo de Anne Frank en Amsterdam, el Campo de Concentración Sachsenhausen en Berlín, el Museo de la Memoria y los Derechos Humanos (MMDDHH) y la Sala de la Memoria de Villa Grimaldi en Santiago de Chile, y el Museo de la Memoria de Montevideo en Uruguay, por mencionar solo algunos, las instituciones se han planteado la necesidad de acopiar objetos auténticos (vestigios) 
-otras veces reproducir facsímiles- y exhibir una parte de ellos con el propósito de contar una historia objetivada/cosificada a través de ellos. Sin ir más lejos, cerca de una nueva conmemoración del 11 de septiembre en Chile, se proyecta la realización de proyectos multidisciplinarios, como son por ejemplo "Piel", de la artista Norma Ramírez, basado en vestigios de detenidos desaparecidos (D.D), (a instalarse en el MMDDHH) e "Infancia en Dictadura" del Colectivo Infancia y Memoria, el cual busca visibilizar la experiencia de la niñez a partir de -entre otros mecanismos- la búsqueda de objetos producidos por niños y niñas entre 1973-1989. Ambas obras reportan, una vez más, que los objetos y las cosas constituyen dispositivos esenciales en el trabajo de transmisión e interpretación de las memorias.

De forma simultánea, encontramos objetos personales o biográficos que por medio de diversos procesos se han convertido en íconos ideográficos, como son por ejemplo el Diario de Anne Frank para el caso del Holocausto, los pañuelos blancos usados por madres y abuelas de Plaza de Mayo para el caso de la dictadura argentina y los lentes de Salvador Allende para el caso chileno, por mencionar solo algunos casos. También, los objetos han venido a dar vida a proyectos de transmisión de memorias, como son los citados en este trabajo; Química de la Memoria ${ }^{2}$, Vestigios ${ }^{3}$ y Arqueología de la Ausencia ${ }^{4}$. Por último, y quizás el más significativo en el marco de este trabajo, en diversos contextos conmemorativos, familiares y colectivos, nos encontramos con objetos y símbolos, fotografías, flores y pañuelos, que portados y significados por sus dueños o sus herederos, han reportado alto provecho desde el punto de vista descriptivo.
A partir de aquí surge el interés por resituar el valor que tienen y pueden llegar a tener los objetos y artefactos en diversas dinámicas, experiencias, performances y proyectos de un fenómeno tan entreverado como es la construcción social de la memoria. Reconocer cómo estos fragmentos físicos de una historia pasada -y que han sobrevivido al tiempo-, al ser usados, activados y puestos en movimiento, pueden llegar a actuar como vectores toda vez que tienen la suficiencia de movilizar procesos individuales y colectivos, cotidianos y políticos. Su activación, es decir su puesta en movimiento, permitiría impulsar procesos que van más allá de las habituadas prácticas de recuerdo y olvido. Si bien el proceso de recordar suele ser el punto de partida de los análisis, es posible identificar otro tipo de fenómenos en los cuales los objetos jugarían un rol medular. ¿Cuál es la biografía cultural de los objetos? ¿Constituyen un umbral para despertar la experiencia mnemónica? ¿Qué fenómenos reportan el uso de estos objetos además del recuerdo individual y colectivo? ¿Puede el objeto biográfico redimensionarse hacia una experiencia de proyecto político?

Para cumplir con los objetivos propuestos, se optó en primer lugar por realizar entrevistas a personas que habían entregado, en forma de donación, parte o todos sus objetos al Museo de la Memoria y los Derechos Humanos de Santiago. El énfasis de estas entrevistas se situó en la biografía de los objetos, rastreando la historia desde su construcción u obtención hasta su traspaso al museo, significando especialmente los motivos de la conservación y donación de piezas de artesanía carcelaria. En segundo lugar, sostuve encuentros con familiares de víctimas desaparecidas de la localidad rural de Paine en la Región Metropolitana, Chile. Su característica diferencial respecto al 
primer grupo mencionado, es que estas mujeres han conservado sus objetos en sus espacios familiares. El énfasis de estas entrevistas también se situó en la biografía de los objetos, rastreando la historia desde su elaboración o adquisición hasta el presente. En tercer lugar, entrevisté a coordinadores de proyectos de memoria en los cuales el objeto constituía motivo central, entre los que cabe destacar los proyectos argentinos Química de la Memoria y Vestigios de Memoria Abierta ${ }^{5}$, y el proyecto nacional Arqueología de la Ausencia de la artista visual Verónica Troncoso. Paralelamente, se realizó un trabajo etnográfico en contextos conmemorativos con el propósito de rastrear el repertorio de objetos usados y activados en cada uno de estos contextos. Finalmente, se desarrolló en Santiago la iniciativa argentina Química de la Memoria, realizando, en agosto de 2013, seis talleres participativos con distintos grupos bajo la consigna de entregar temporalmente un objeto que representara el recuerdo subjetivo del período de la dictadura. Todos los objetos y sus historias fueron expuestos en el Museo de la Memoria y los Derechos Humanos de Santiago de Chile en los meses de agosto y septiembre del año 2013.

El artículo está dividido en tres partes: a) Definición multidisciplinaria de las nociones de memoria y objetos; b) Notas para reflexionar en torno a los movimientos y agencias de los objetos en los contextos conmemorativos de memoria y c) Notas finales para una proyección de los objetos en trabajos de antropología y memoria.

\section{De la memoria y los objetos}

Los objetos, aquellos vestigios del pasado que sobreviven a pesar de todo, encarnan biografías, registran una o más historias rastreables a través de sus dueños/as. Los objetos son los rastros y huellas de una historia, es lo que va quedando al presente de una vivencia del pasado. En efecto, si lo ya sido, lejos de constituir una experiencia intemporal progresiva, es un tiempo visible y actual, localizado y corpóreo, los objetos constituirían cuerpos fundamentales y objetivos de estos pasados vivos.

Abordar los objetos en su vertiente más teórica, implica tener en cuenta que ellos forman parte constituyente de nuestra vida cotidiana. Esta es su espacio de aparición y existencia por excelencia, lo cual ha llevado a pensar a autores como Francisco Tirado (2001), que la vida cotidiana no puede darse al margen de los objetos. Es más, el autor sostiene que sin lenguaje, hábitos y uso de objetos "no hay vida cotidiana en absoluto y, por supuesto, no hay ni socialidad ni, lo que es más grave, reproducción de la realidad social" (Tirado, 2001:144). Para el sociólogo francés Maurice Halbwachs (1990), estos objetos cercanos de contacto diario, nos entregan permanencia y estabilidad, mientras que para De Certeau (1999), estos objetos cercanos permitirían reconocer ahí, "en el abigarramiento de los trozos" una novela familiar, la circulación de experiencias colectivas o individuales. Por su parte, Mead (2003. En Tirado, 2001) sostiene que la realidad y su vida cotidiana al ser eminentemente simbólica, requiere de las cosas y los objetos para su definición, mantención y activación. No obstante, va más allá; apunta a la necesidad de aquella experiencia de interacción y contacto concreto con los objetos, para la conciencia y autorreflexividad del self. Se trata 
de una sociología del acontecimiento y de la percepción.

En este contexto de reflexión entre objetos y vida cotidiana, Jean Baudrillard (2010) nos ofrece, sin duda, uno de los tratados más importantes y nos advierte que los objetos funcionales carecen de autonomía, siendo la acción del hombre lo que vuelve lo abstracto en funcional, es decir, los dota de una categoría de presencia. Mientras que estamos rodeados de objetos funcionales, también convivimos con objetos no funcionales, objetos barrocos, folclóricos, exóticos, antiguos, los cuales "parecen contradecir las exigencias de cálculo funcional para responder a un deseo de otra índole; testimonio, recuerdo, nostalgia, evasión. Se siente la tentación de descubrir en ellos una supervivencia del orden tradicional y simbólico" (Baudrillard, 2010:83). Se trata de objetos que también forman parte de la modernidad, conviven con los objetos funcionales, pero con un sentido de funcionalidad convertida en historicidad en tanto objeto antiguo. Para Baudrillard el objeto funcional es moderno y útil, pero sobre todo, se deja entrever un objeto en serie, repetido y anónimo. Mientras tanto, el objeto afuncional es mitológico, vestigio de una creación y de una historia cultural, artesanal, y por ende único e irrepetible.

Para comprender la relación entre objetos y prácticas mnemónicas ${ }^{6}$, nos desplazamos a las ideas de Pierre Nora (2009), quien sostendrá una primera clave: la memoria enmarcada en la vida cotidiana, asociada a un contexto íntimo y familiar, siempre se enraíza en lo concreto: espacios, imágenes y objetos. Los objetos son soportes que guardan memoria y dan materialidad y permanencia a las prácticas mnemónicas, donde familiares y diversos grupos conser- van, exponen, instalan, significan, intercambian o depositan objetos que otorgan permanencia y estabilidad en los ámbitos cotidianos de los sujetos. Como apunta Radley (1990), los objetos están unidos de manera inseparable a la memoria, permiten establecer un vínculo con el pasado y por ende, tendrían relevancia en la elaboración de la memoria. "Los artefactos y el entorno manufacturado también existen como expresión tangible de la base a partir de la cual se recuerda, como aspecto material de entorno que justifica los recuerdos así construidos" (Radley, 1990:66). Por ello hay objetos más significativos que otros (dominantes) puesto que tienen el poder de re-evocar creencias, sentimientos, imágenes, vivencias y episodios.

Por su parte, los objetos en contextos específicamente colectivos son profundamente significativos y enunciantes. En la acepción de memoria $^{7}$ sugerida por Félix Vázquez, donde memoria es proceso y producto construido a través de las relaciones y prácticas sociales, y donde el lenguaje y la comunicación ostentarían un papel fundamental, los objetos emergen como senderos ineludibles de lo que Vázquez entiende como construcción social de la memoria. Vázquez (2001) apunta que lo social no radica en los sujetos sino que entre los sujetos, es decir, en una trama de significados construida conjuntamente. En esta referencia, donde la memoria no sería una restitución anacrónica del pasado, sino que una "reconstrucción presente realizada y actualizada a través del lenguaje y las prácticas sociales" (Vázquez, 2001:9), los objetos, en su carácter representacional, refuerzan las prácticas mnemónicas, especialmente en los contextos de ausencia, donde lo ausente ya no está, y por ende, en virtud que la restitución de lo desaparecido es imposible, los objetos actúan como puentes y senderos hacia un 
pasado poroso y diluido por el contexto invariable que imprime la condición de la ausencia.

En este escenario, dada su especificidad, los objetos serían nudos convocantes de recuerdo toda vez que son un tipo de materialidad contenedora de situaciones significativas que facilitan la recuperación de trazos y tramas de pasados cercanos y lejanos. Según esto, los objetos servirían de referencia material para los recuerdos y por extensión, todos los recuerdos estarían depositados (materializados) en objetos. Cada objeto contiene una anécdota o acontecimiento que podría llegar a reconstruirse y actualizarse en el acto de conmemoración ${ }^{8}$, ayudando a reconstruir el pasado. Considerados de esta manera, los objetos tienen la capacidad de "cosificar", en el sentido de "personificar" pensamientos, acontecimientos y experiencias que individuos y grupos producen, portando anécdotas y episodios que de otra manera se perderían o diluirían en el tiempo, o simplemente, caerían en el desuso y la desmemoria.

En esta línea, autores como Turner y Todorov invitan a pensar sobre el objeto y el símbolo como acción, por ende, nos inducen a pensar sobre sus usos y significados. Al respecto vale la pena ejemplificar con el trabajo de Ludmila Da Silva (2006) titulado "Las marcas materiales del recuerdo", en el que reflexiona sobre los pañuelos de las madres y abuelas de Plaza de Mayo, objetos que se organizan como símbolos de poder de interpelación al Estado y a la sociedad civil, una representación de memoria frente a la desaparición, un territorio de conquista y ritual de cara al dolor. El pañuelo sería de esta forma un objeto material concreto que prescribe prácticas y convoca identidades, un deber de memoria, una forma de hacer política. En esta trayectoria, el pañuelo blanco simboliza un territorio de memorias dinámico, conflictivo, cambiante y poderosamente convocante.

De este modo, la relación entre objetos y memoria nos conduce al campo político de la acción y la representación. Para comprender la posible incidencia del objeto en el espacio de lo político, seguimos el texto "El deseo de la memoria" de Osorio y Rubio (2006), quienes señalan que en aquella búsqueda y rememoración (anamnesis) marcada por traer lo ausente en la distancia al presente, existe una enunciación de deseo en que se redimensiona la memoria vital hacia una acción política. De aquí, vincula el concepto pedagogía de la memoria, la cual se "proyecta como el intento de validar lo humano en lo social y por ello surge en un "contexto político de significación", como contrapunto crítico del orden social para configurar la ciudadanía memorial, constituida por hombres y mujeres, sujetos críticos que deben, desde la memoria viva, desnudar el potencial ideológico de toda estrategia totalizadora que legitime el olvido" (Osorio \& Rubio 2006:29). Osorio y Rubio van más allá de Vázquez, validando una noción donde hacer memoria, en su sentido público, crítico y empoderado, que permitiría resituar a las prácticas mnemónicas en un sentido politizante.

En esta idea, el objeto trasciende su función objetivadora y testimoniante y pasa a ocupar un lugar dinámico donde debe ser activado, implicándose en un proceso de activación de procesos. Aquí los objetos no son considerados como cosas carentes de incidencia, sino que sus posibilidades se prolongan hacia y desde la acción y de su poder de cosificación de tramas y trazos de nuestro pasado. Esta constatación será reforzada por ideas de autores del campo antropológico ${ }^{9}$ y socioló- 
gico, entre los que destacan Appadurai, Gell y Latour. Sus ideas se vuelven trascendentales desde una perspectiva metodológica, por cuanto alientan a pensar cómo el objeto puede ser considerado un indicio de conocimiento en las dinámicas socioculturales de la memoria, cómo pensarlo, abordarlo y utilizarlo ${ }^{10}$.

\section{Las voces de los objetos: Notas para reflexio- nar en torno a los movimientos y agencias de los objetos en las prácticas de memoria}

A partir de los distintos caminos seguidos en esta investigación, de manera inicial es posible afirmar que los objetos son ingredientes fundamentales de la cultura de la memoria. Al consignar esta realidad, se hace impostergable revertir su estado de parcial exclusión de los estudios de memoria, y resituarlos en su importancia y trascendencia, no ya en su evidente participación de la cultura mnemónica -lo que ha quedado en evidencia-, sino en su relevancia para los ejercicios disciplinarios de explicación y comprensión de las prácticas mnemónicas de sociedades posconflicto y sus materialidades indefectiblemente asociadas.

Tras las observaciones, relatos y testimonios registrados y analizados en el marco de esta investigación, se gestan reflexiones específicas que van más allá de lo recientemente expuesto, las cuales, lejos de ser concluyentes, intentan rastrear ciertas estrategias y operaciones dibujadas a partir de la activación de los objetos. Se trata de situaciones y formas de acción en que se va definiendo el devenir de dichos vestigios. De esta forma, se identifican operaciones claves y recurrentes de las biografías culturales de los objetos, entre las que cabe destacar su elaboración, adquisición, obsequio, legado, herencia, socialización, exhibición, mostración, registro fotográfico, conservación, desprendimiento, donación, pérdida, recuperación, atesoramiento, ocultamiento, hallazgo y desaparición, por mencionar algunas operaciones reiteradas que devienen en procesos de agencia individual y social.

En esta senda de exploración de significados, usos y movimientos de los objetos, nos fuimos encontrando con distintos niveles contextuales; objetos elaborados al interior de la cárcel, objetos exiliados, objetos desaparecidos, objetos conservados, objetos escondidos, objetos heredados, objetos donados, objetos encontrados, objetos vendidos, objetos perdidos, objetos exhibidos, objetos reproducidos, objetos copiados, objetos fotografiados y registrados, objetos disputados... Cada una de estas acciones, momentos y acontecimientos específicos que encadenan una biografía cultural, a su vez, moviliza y activa otros procesos individuales y colectivos cotidianos y politizantes. Se trata de entender que cada acción en que son hechos participar los objetos, reporta otros movimientos que influyen en la realidad, lo que va más allá de la constitución de un relato histórico, como únicamente podría suponerse.

¿Qué movimientos agencian estos objetos? ¿Qué posibilidades brinda su uso y circulación? ¿Qué historias condensan y como objetivan dichos acontecimientos? ¿Qué moviliza el objeto cuando es puesto en escena? ¿Qué distingue e identifica al objeto de los lugares y sitios de memoria? ¿Por qué reportan tanta importancia en los contextos de exhibición? ¿Por qué sus dueños deciden en ocasiones entregarlos y en otras conservarlos? ¿Qué revela, nutre y condiciona la presencia de los objetos en espacios cotidianos, institucionales, familiares y colectivos? Tras oír los relatos de dueños y dueñas de 
objetos entregados y/o conservados, emerge el esperado primer vínculo entre objeto y actividad mnemónica. Recordar es volver a pasar por el corazón, traer esas imágenes del pasado al presente. ¿Cómo ayudan los objetos a impulsar estos procesos de reminiscencia?

Si los objetos se distinguen por su poder de cosificación, quiere decir que todo objeto porta una historia y que cada historia está objetivada en un objeto. Al mismo tiempo, todos los objetos condensan recuerdos y todo recuerdo podría estar contenido en uno o más objetos. Así, cabe otorgar a los objetos un carácter aurático, el cual se convierte en el punto de partida para demostrar que en el acto de recordar los objetos son vehículos altamente significativos.

En situaciones signadas por un pasado de dolor, quiebres y ausencias, el objeto constituye un elemento disparador de recuerdos o fragmentos de recuerdos, constituyendo un registro tangible del pasado, lo material de lo ya sido. La importancia de los objetos sobrevivientes, adquiere mayor fuerza en situaciones de desaparición y ausencia de cuerpos, cuando muchas veces lo único que queda de los ausentes son sus pertenencias, las cuales además tienen ocasionalmente ese rasgo accidental de haber sido lo último usado, tomado o guardado momentos antes de la tragedia, y por ende, desde el presente siempre se trabaja desde la imposibilidad de la ausencia. En ese escenario, los objetos del pasado son altamente productivos para el desencadenamiento de recuerdos en un nivel individual y familiar, como así mismo colectivo e institucional.

Los testimonios expresados por las mujeres de D.D de Paine, desvelan que en este contexto de ausencia los objetos constituyen una cinta transportadora hacia determinados recuerdos de hitos, personajes o lugares del pasado, y es por ello que decimos que el objeto es un dispositivo reactivador por relación: el objeto designa un elemento con interioridad que activa por conexión la rememoración de trazos y trozos del pasado en él condensados. Cuando los recuerdos son incompletos, fragmentarios 0 disgregados, el objeto, en tanto vestigio que permanece completo y auténtico, abre la puerta para el trabajo de rememoración. Cuando existe imposibilidad o dificultad de socializar lo vivido, como es el caso de los familiares de desaparecidos de Paine, la cuota de sustantividad y objetividad del objeto se convierte en un elemento de posibilidad para compartir fragmentos del pasado. Porque el objeto convocante incluye el cuerpo y sus vivencias; el objeto lo puedes volver a tomar, a oler, a escuchar y a guardar, y con ello, la persona se abre hacia la posibilidad de recordar y contar.

¿Qué se vuelve a pasar por el corazón? En el caso de los sobrevivientes de prisión política, los objetos agencian el recuerdo de la experiencia carcelaria y del exilio, representando esos objetos fragmentos de historias relacionadas con ese período de su vida. En ciertos casos, al compartir la historia del objeto, se revelan situaciones significativas asociadas estrictamente a ese objeto, facilitando su recuperación, mientras que en otros casos, la socialización del objeto permite vincular el recuerdo unido a una totalidad rememorante, es decir, abriría la posibilidad de despertar recuerdos que irían más allá de la anécdota o acontecimiento asociado al objeto.

Hombres y mujeres que aportaron con sus testimonios a este trabajo, permitieron evidenciar que al momento de poner en valor sus objetos, el relato se ampliaba desde la anécdota del 
objeto mismo hacia otras dimensiones, como por ejemplo, hacia las personas involucradas y los lugares en que estas historias habían ocurrido. Esto nos permite constatar cómo el objeto, en su despertar fragmentos del pasado, aporta a la significación de experiencias individuales y colectivas, donde lo que se recupera no es tan solo la historia de ese objeto antiguo, sino que permite hacer memoria de otros acontecimientos en su sentido colectivo. Al mismo tiempo que el objeto permite cosificar aspectos históricos, estos posibilitan personificar pensamientos y afectos sobre esas experiencias. Por otra parte, están los objetos que vuelven a pasar por el corazón episodios asociados con la muerte: desaparición, dolor y ausencia. La activación de estos objetos en diversas instancias como conservación y socialización a través de exhibiciones, talleres y narraciones, transportan a sus dueños a episodios que tienen que ver casi siempre con signos de la ausencia. Los familiares de las víctimas, y con mayor fuerza los familiares de víctimas cuyos restos persisten en estado de desaparición, emprenden su trabajo de memoria siempre desde esta imposibilidad.

En este contexto, los objetos pertenecientes a personas desparecidas son cosas que por lo general no pertenecían en el pasado a sus actuales dueños, sino que son vestigios heredados, reapropiados y conservados por sus familiares y amigos luego de su muerte. Aquí nos encontramos con dos tipos de objetos; por una parte aquellos vestigios que en vida constituyeron objetos de cotidianidad; ropa, artefactos personales, libros, discos, documentos, fotografías, utensilios, etc., pero al mismo tiempo nos encontramos con aquellas cosas usadas accidentalmente por última vez; "el último libro que leyó", "el reloj que llevaba puesto y que sigue funcionando", "el lápiz con que escribió antes de salir". El guante de un padre ejecutado, que heredado por su hijo luego es llevado en una maleta al exilio, y que luego retorna, constituyendo la única prenda sobreviviente a la cadena de acontecimientos. Un guante sagradamente conservado, que guarda el olor del padre, abre el proceso de recuerdo hacia el episodio de ejecución, pero también hacia tramas de la vida cotidiana que se mantienen vivas en la memoria del entrevistado.

La activación de estos objetos transporta a familiares y amigos a momentos vitales como escenas familiares, laborales, educativas y políticas. Aquí el objeto al ser socializado, abre una puerta para que las personas signifiquen un tiempo inmemorial en que los familiares aún estaban presentes, constatando a través del objeto la realidad incontestable de la ausencia. Por otro, y por sobre todo, los objetos activados tienen que ver con una memoria funeraria, y por ende, el recuerdo que agencia el objeto está ligado a momentos específicos de la trayectoria de vida de estas personas. De esta forma, el objeto permite recordar a alguien que alguna vez existió, su sobrevivencia física permite objetivizar de la forma más ineludible el momento que hizo posible la ausencia de sus dueños.

Siguiendo en la trama de posibilidades que abre el objeto en el contexto de ausencia y pérdida, se aprecia también una función sustituyente. Sustitución significa poner a alguien o una cosa en lugar de otra persona o cosa para desempeñar su función. De esta forma, en su sentido más elemental, sustituir refiere a cambiar una cosa ausente por otra, intentando llenar la ausencia por medio de su reemplazo por un elemento que vendría a sustituir dicha 
carencia. En los testimonios y relatos compartidos en el contexto de entrevistas y talleres de Química de la Memoria, se reiteraron frases como "tener la guitarra es como tenerlo a él" o "tengo sus lentes en la entrada porque me acompaña", las cuales dialogan sobre el poder sinecdótico de reemplazo simbólico que revierte el objeto en ciertos contextos. En este sentido, los familiares tienen objetos que consideran objetos sagrados (tesoros), que vendrían a adquirir un estatus de personificación, al llenar alegóricamente un espacio cotidiano que ha sido vaciado (extirpado). El poder de estos objetos sagrados de absorber la imagen "absoluta" de los que no están, aportaría a la cotidianidad de algunos familiares con su representación siempre simbólica por sustitución ${ }^{11}$.

Para avanzar, continuamos con la posibilidad de reivindicación tras el uso de objetos en el marco de las prácticas mnemónicas. Reivindicar; reclamar algo a lo que se cree tener derecho; argumentar a favor de algo o de alguien. Reivindicar es recuperar lo que a uno le pertenece y no posee. Por extensión, se identifica la construcción de una verdad o versión del pasado sobre determinados sujetos y condiciones históricas, y sobre las cuales los mismos protagonistas exigen una reconstrucción a favor de su memoria. En este escenario, a partir de los testimonios recogidos en el marco de la investigación, identificamos la posibilidad que abren los objetos de reivindicar el imaginario delictivo asociado a la experiencia carcelaria. De manera general, las víctimas de represión han sido incorporadas en relatos históricos totalizantes y míticos que construyen una imagen actitudinal negativa de su experiencia en prisión, la que esconde y omite historias cotidianas que lejos están del discurso dominante; "eran flojos", "eran criminales", "eran terroristas". Y en este contexto, muchos sobrevivientes de los recintos carcelarios demandan o desean reivindicar una identidad que les ha sido deliberadamente arrancada.

En este escenario, los objetos exhibidos en el Museo de la Memoria y los Derechos Humanos, han venido a funcionar como vestigios demostrativos de aquella versión de realidad que se busca recuperar. Estos objetos permitirían a sus dueños, mediante su exposición, reclamar y argumentar a partir de la constatación de su sustantividad y objetividad, a favor de una imagen positiva que les permitiría recuperar una imagen que el metarrelato histórico oficial de la dictadura les ha quitado. De forma concreta, la exhibición de objetos realizados entre rejas, de acuerdo al testimonio de varios ex presos y presas, permitiría reivindicar una imagen positiva al exponer productos y obras creadas por ellos y ellas, contrarrestando la tradición que los posiciona como sujetos antisociales, criminales, flojos, desprovistos de capacidades e inhabilitados socialmente. Un segundo momento tiene que ver con devolver la identidad a las víctimas previas al momento de su victimización -relacionado con una condición de humanidad-, reportando la posibilidad de rescatar una identidad banal o cotidiana al constatar a través de sus pertenencias, que eran personas comunes, mujeres, hombres, obreros, estudiantes, deportistas, trabajadores, padres, madres, que usaban cosas en su día a día, usaban rasuradoras, leían, escribían, comían, escuchaban música, viajaban, etc. Que usaban cinturones, que tomaban café, que todos los días se levantaban al escuchar un despertador, que escribían con un lápiz, con un lápiz que puede ser igual al mío, con un reloj tal como el que tengo en mi velador, en una taza similar a la que uso cada día, un cinturón tan igual como el que 
puedo llevar puesto, una madre como yo, un estudiante o un trabajador cuya humanidad es idéntica a la mía.

"Que esa imagen se contraponga a lo que ellos están mostrando de esas personas en esa vitrina, que digan, pero esta persona no puede haber sido tan terrorista si era alguien que jugaba en todas sus horas libres, voleibol, por ejemplo, o que leía los cuentos de niños, o que cuando la detuvieron estaba en su casa tejiendo y no estaba poniendo una bomba" (Mujer entrevistada por proyecto de Sala de la Memoria de Villa Grimaldi, 2011).

Esta activación del objeto permite agenciar una reivindicación de la imagen pública y social de las víctimas por identificación, es decir, inquietar al visitante a partir de la constatación de aquellas víctimas como personas, como individuos, previas a su militancia, detención, desaparición y/o construcción de estatuto victimizante.

Explorando otras posibilidades de agencia del objeto, nos aproximamos a una tercera idea: que al presente y de manera general, la recuperación y transmisión del pasado consigue fundir en un relato unificador a la mayoría de las víctimas. Ello daría origen a un desdibujamiento de las realidades biográficas en favor de una historia totalizante que procesa grandes unidades de representación del pasado como son por ejemplo el exilio, la resistencia y la desaparición. En este contexto, si bien los memoriales buscan individualizar por medio de la inscripción de los nombres, las narrativas de la dictadura ${ }^{12}$ han tendido a fundir las memorias individuales en una gran memoria colectiva-nacional. Así, es posible observar cómo las memorias individuales y familiares, quedan fundidas en un metarrelato que tiende a diluir las especificidades biográficas de los sujetos.
Identificar significa individualizar la experiencia. Dar los datos necesarios para ser reconocido/a. En este sentido, la palabra identidad posee una dualidad: por una parte, se refiere a características que nos hacen percibir que una persona es única (una sola y diferentes de las demás), y por otro lado, alude a las características que poseen las personas y que nos hacen percibir que no somos lo mismo que otros. En nuestra vida diaria, producimos y usamos una serie de documentos institucionales que permiten atestiguar dicha identidad y constituyen los elementos a través de los cuales los otros constatan dicha unicidad. Abierta esta posibilidad, adquiere sentido que algunos de los objetos conservados y donados se relacionen con una necesidad de individualización. Carnets de identificación, documentos de militancia, permisos de exilio y retorno, certificados de nacimiento y defunción, permisos de trabajo en el exilio, documentos de permiso de residencia en el extranjero (exilio), ingreso a la universidad y documentos de membresía deportiva, fueron parte de los documentos puestos en valor en los encuentros. En todos ellos aparece el nombre, números de identidad, fechas de nacimiento, descripción y lugares asociados, toda información única para afirmar experiencias del pasado. En este sentido, es interesante observar cómo los objetos de identidad permitirían a sus dueños traer al presente su unicidad e ir más allá de su inclusión en un relato histórico que tiende a convertirlos en nuevos NN. Y es en este contexto, que para algunas personas se vuelve sustancial el reconocimiento social de sus historias a partir de la constatación de la información personal presente en este tipo de documentación.

Dejamos la facultad identitaria para dar paso a la relación entre objetos y reparación. Nos 
detenemos brevemente para hacer la distinción entre reparación efectiva y la condición de sentirse reparado (Montero, 2012). La primera, plantea que se puede corregir el daño en su naturaleza traumatológica; restaurar el estado previo de afectación y restituir a la persona en su "normalidad"13. El debate ha permitido constatar que la reparación efectiva, en las prácticas cotidianas, es sencillamente es imposible.

\footnotetext{
"Nada vuelve atrás, nada del pasado puede ser cambiado, está afirmado en la realidad honda y central (...) Hay daños que deshumanizan de tal forma que no hay forma de sobreponerse a ciertas rupturas y violaciones de la dignidad. Su identidad no solo queda marcada, sino que queda atrapada por lo que ha vivido" (Montero, 2012:33-34)
}

Sin embargo, la reparación sí puede desplegarse en una dimensión simbólica. Tal como sostiene Montero, recordar públicamente permitiría reparar y resarcir a los afectados. Es probable revisar el pasado para un reordenamiento de la vida psíquica y social de las personas y para un reconocimiento social del daño, por lo tanto, estamos hablando de una reparación a partir de procesos de reelaboración de lo padecido. En este sentido, la posibilidad de compartir mi experiencia con otros, accediendo a un lugar de exteriorización y socialización de la experiencia que en determinados contextos no ha sido posible, sí puede abrir una puerta para que las personas se "sientan reparadas".

En esta premisa, la presencia de objetos en museos tiene una importancia determinante, por cuanto en estos espacios se abre la posibilidad de que mi experiencia individual devenga en experiencia pública, trascendiendo del espacio privado-íntimo a uno colectivo y social, donde otros podrán conocer y saber mi historia a partir del objeto, lo cual tiene que ver con que mi experiencia condensada en el objeto se prioriza por sobre otras, y con ello, se hace importante no tan solo para mí sino que se vuelve importante para otros. Pero también los objetos resultan altamente significativos en instancias que impulsan procesos de elaboración (espacios terapéuticos y/o participativos), donde los objetos contribuyen indicialmente al trabajo de elaboración social del trauma y el daño. Su activación puede ayudar a reactivar fragmentos de recuerdo y despertar trazos de memoria de las vivencias que, en muchas ocasiones, no sería posible sin ellos. Por la cuota de objetividad, sustantividad y personificación del objeto, su activación puede aportar al desarrollo de trabajos específicos orientados a recomponer al afectado en su capacidad de relacionarse con otros y con la sociedad, además de constituir un espacio de posibilidad de narrar historias muchas veces invisibilizadas y silenciadas por la persistencia de situaciones de miedo y estigmatización.

Para ir más allá, conducimos el análisis hacia el poder de transmisión de los objetos de memoria. Transmitir es hacer llegar a alguien mensajes o noticias. Conducir o ser el medio a través del cual se pasa o lleva algo a otro lado. Como bien ha expresado la comprensión semiótica, los museos a través de sus recursos museológicos buscan hacer llegar un mensaje a sus visitantes. Para eso se construyen los guiones y se exhiben los objetos. Ambos tienen la capacidad de revelación de una parte de la memoria y la historia, haciendo que esa selección sea objetivada y conducida hacia los intereses de quienes interactúan con dichos elementos. De esta manera, las prácticas de memoria con soportes de objetos, sean artísticos, biográficos o sociales, son capaces de incidir en cómo las sociedades interpretan su pasado desde el 
presente. Al respecto, encontramos dos niveles. En el primero, biográfico, resulta sumamente relevante la acentuación de los objetos y las prácticas desde abajo, de las microhistorias o relatos biográficos para poner en valor historias personales, donde el movimiento está dirigido a fortalecer el saber histórico localizado e individualizado. Por otra, el objeto al ser activado institucionalmente, esto es recomoditizado en términos de Kopytoff (1991), adquiere una nueva identidad. En el museo, el objeto deja de ser lo que era en sí mismo y comienza a ser en representación de algo. El objeto en vitrina, lejos de su lugar de origen, conduce a una ausencia, a otro objeto y a otro espacio y tiempo. Por ello se insiste en cómo los objetos representativos de períodos conflictivos sirven a las instituciones en la construcción de una representación y significación distinta de su esencia y que le trasciende, dotando al vestigio de un nuevo contexto de interpretación. En esta metamorfosis, los objetos consagrados por los espacios institucionales tienen la fuerza de plasmar un imaginario elegido y dirigido, los cuales apoyan un discurso que generalmente se distancia del contexto en que fueron creados y usados. Así, estos objetos prototípicos que alguna vez constituyeron piezas gravitantes de experiencias personales, al entrar en el museo se convierten en entidades directoras de mensajes, pasando de ser objetos de nuestra atención a instrumentos de nuestra intención.

El último punto de interés es la capacidad demostrativa de los objetos, la cual no tiene que ver tanto con una capacidad de movilizar procesos intersubjetivos, como con la potencialidad del objeto como partícula probatoria de una verdad en un nivel más subjetivo. En el contexto de los procesos judiciales e institucionales, como por ejemplo comisiones y juicios, pero también en la presentación de testimonios dados por familiares y sobrevivientes en contextos informales, existe siempre la velada exigencia de demostrar su verdad por medio de materialidades (pruebas), ya que la memoria oral no tendría la fuerza suficiente para probar los hechos. Como en toda investigación, se requiere de un correlato material, las pruebas perceptibles, para dar sustantividad a las aseveraciones. De esta forma, los objetos encontrados en el marco de investigaciones judiciales, como es el caso de los lentes ópticos que usaba un hombre painino el día de su detención en octubre de 1973, vienen a constituir restos culturales que se agregan como pruebas al desarrollo del proceso. Pero por otra parte, en el sentido que importa sustancialmente en esta investigación, estos lentes también constituyen una prueba tangible para sus familiares y sociedad. En un contexto en que la comunidad y sociedad por extensión, niega el testimonio de los familiares y la fidelidad de sus declaraciones, la cuota de objetividad y sustantividad del objeto, avalada por el marco legal de las investigaciones, aporta con mostrar y hacer ver que una verdad particular constituye una verdad judicial, trascendiendo de invención a verdad. En este contexto, estos vestigios culturales encontrados y recuperados por los familiares, se convierten en una voz probatoria, la cual es usada en los círculos familiares y sociales para exponer justificadamente que lo que estoy diciendo es indudablemente cierto. Así, estos lentes muy bien guardados en una caja de madera, ocupan un sitio central. Ubicados en el living, cerca de la entrada de la casa, se encuentran en el centro de una mesa acompañados de varias fotografías del marido desaparecido. Los lentes están ahí para que todos y todas puedan constatar que constituyen restos encontrados en pericias judiciales. 
Por tanto, estos objetos que son guardados por familiares de víctimas de la represión constituyen objetos demostrativos que agencian credibilidad al relato de sujetos cuya voz ha sido históricamente invalidada. El objeto encontrado trasciende en objetivo social-probatorio.

Es importante notar que estas indagaciones sobre las posibles agencias del objeto en contextos conmemorativos de memoria, han sido tomadas de un repertorio de tramas de significación acotadas a esta investigación. En este sentido, es indudable que los objetos ofrecen otras posibilidades, otras voces, tan solo debemos resituarlos en su importancia para avanzar hacia otras esferas de actuación.

\section{Notas finales para una proyección de los objetos en trabajos de antropología y memoria}

De alguna manera, se hace necesario insistir en que los objetos constituyen cuerpos altamente necesarios y significativos para la comprensión de las prácticas mnemónicas en contextos posconflictos, marcados por experiencias de violencia, ausencia y permanente tensión entre la sociedad y el Estado. Objetos usados por los individuos y grupos en prácticas de resistencia, pero también por las esferas institucionales en diversos proyectos de transmisión de memoria y establecimiento de un relato histórico. Por ello, es vital reportar que estos vestigios pueden pasar de objetos de nuestra atención a instrumentos de nuestra intención.

En sus diversos niveles de actuación, los objetos forman parte estable y constante de escenarios conmemorativos, de aquellos espacios o lugares de memoria, de museos, de memoriales, de cementerios, de marchas, de baúles, de instalaciones, de obras de teatro, de archivos. El uso de objetos en procesos y prácticas de memoria heredados y representativos de pasados complejos, que siguen siendo pasados vivos, pasados presentes, resulta un indicador de su importancia. El uso de objetos en prácticas reconstructivas de recuerdos individuales y colectivos, su exhibición en museos y espacios de memoria y su participación constante en expresiones y teatralidades públicas, persuaden del valor que tienen estos dispositivos al momento de revisar, interpretar, transmitir y utilizar la memoria.

Al respecto, cabe destacar, por ejemplo, la experiencia del Museo del Holocausto de Washington, donde el visitante elige una víctima, toma un texto con su historia, y a lo largo del recorrido va buscando objetos que pertenecen o tienen que ver con esa víctima. En un sentido cercano, la Sala de la Memoria de Villa Grimaldi también apela a la identificación de historias personales a partir de la exhibición de pertenencias particulares, donde la contemplación de dichas huellas materiales impulsa la reflexión ante la constatación ese podría haber sido yo. Retomando los proyectos con objetos, que no necesariamente son exhibiciones estáticas, las iniciativas argentinas Vestigios, Tesoros y Química de la Memoria, constituyen experiencias de puesta en valor de objetos biográficos que también revirtieron procesos subjetivos e intersubjetivos trascendentales para sus participantes.

En este punto resulta importante destacar que si todos tenemos objetos que conservamos del pasado, estos pueden constituir un punto de partida metodológico y epistemológico de cara a provocar, comprender y reflexionar en torno a las dinámicas mnemónicas. Los objetos son vehículos que nos ayudan a profundizar en el nivel de información acerca de las historias vitales y colectivas, promoviendo un trabajo de 
construcción social de la memoria, en el sentido sugerido por Vázquez (2001). En este contexto, es indispensable que los objetos sean considerados desde su poder biográfico, para lo cual es necesario rastrear su vida cultural, lo que implica una investigación y comunicación de los distintos usos y significados que estos tuvieron o recibieron a los largo de su existencia hasta quedar guardados, expuestos, coleccionados y/o desaparecidos. Estos objetos nos hablarán de historias posiblemente excluidas y ausentes de las narrativas totalizantes, de experiencias de vida cotidiana.

Pero pensar en los objetos, es también interrogar por la manera en que pueden aportar a comprender el drama social heredado de la violencia sobre los cuerpos y sus consecuencias colectivas, yendo más allá de la dimensión subjetiva. Ello nos lleva a preguntamos ¿Cómo pueden los vestigios contribuir socialmente a reflexionar sobre aquello del pasado que no se puede borrar? El valor del objeto reside en su resistencia a la desaparición a pesar del encadenamiento de situaciones irruptivas que le rodean. En el presente, el objeto sobreviviente deviene en testigo y huella de aquello que ya no está, de aquello que ya pasó, convirtiéndose en el punto de contacto material entre dos polos: de lo que alguna vez fue y de lo que sigue presente en nuestra memoria pero de forma inaprensible. Estos objetos son prueba de la inexistencia de sus antiguos dueños -ahora ausentes-, y en ese contexto, son significativos en la reconstrucción de las historias e identidades, donde objeto y memoria se funden para generar un ejercicio de reminiscencia emergido desde la concreta materialidad.

Siguiendo en esta línea, la pluralidad del objeto evidencia su valor para los estudios antropológicos. Como instrumento disparador, el objeto puede constituir un remedio al silen- cio, omisión y supresión. Dicho con otras palabras, en instancias participativas, en el sentido de pedagogía de la memoria de Osorio y Rubio, el objeto permitiría hacer memoria, activar el trabajo de reminiscencia. Reunidos en talleres o en contextos de entrevistas, las personas pueden iniciar su trabajo mnemónico a partir de los objetos. Fotografías, vestigios útiles y antiguos, cartas, documentos, ropas, pueden aportar al desencadenamiento de aquello que en ocasiones se vuelve tan difícil de organizar y expresar. Contar para qué fue usado, cómo fue adquirido, cuándo fue recuperado, por quién fue regalado... revelar su biografía constituye una herramienta hacia la recuperación del pasado. El contenido específico revelado puede restringirse a la historia de ese objeto, no obstante, lo más posible es que el hilo de recuerdos tejidos a partir de la remembranza del objeto teja una red relacional con otros acontecimientos y personajes. El uso del objeto multiplica y pluraliza la posibilidad de recuperar aquello ausente, desaparecido y cerrado.

En un sentido recíproco, se constata que los objetos son un fondo de información para aproximarnos al pasado. Así, en el trabajo etnográfico que aborda las prácticas y materialidades de recuerdo, uno de los principales desafíos es penetrar en pasados signados por tramas de trauma y dolor. Abundan los silencios y olvidos, -obligados y jurídicos-, que impiden realizar mecánicamente el trabajo de "recolección de información" imperioso para quienes investigamos. La infortunada memoria que se busca indagar y recuperar, presenta esta dificultad, por ende y ante tales circunstancias, es preciso fortalecer vías de acceso complementarias. $Y$ es aquí donde la concreta tangibilidad del objeto puede constituir un ingrediente esencial para asistir el trabajo etnográfico. 
Con el fin de comprender esta fuerza impulsora que provee el objeto al trabajo etnográfico, citamos a Guerrero (2002), quien establece la distinción entre etnografía clásica y etnografía connotativa. La primera, de naturaleza funcionalista, sería una "etnográfica de espejos, como la ha llamado Rosaldo, en la que a través de las descripciones de los etnógrafos se verá el reflejo de lo que, se supone, es la totalidad de la vida de una cultura" (Guerrero, 2002:14). En contrapunto, la segunda descubre la necesidad de escuchar las propias y múltiples voces de los actores. La característica sobresaliente de la etnografía connotativa reside en constituir una herramienta de trabajo para los propios grupos estudiados, "para que puedan leerse a sí mismas y así avanzar en la construcción de una mirada propia y escuchar las voces de los actores constructores de cultura"
(Ídem: 7). En ese contexto, los objetos constituyen contenidos específicos y concretos para estudiar las tres categorías de análisis señaladas por Guerrero: espacialidad, temporalidad y sentido. Propio de esta orientación, es pensar cómo el objeto contribuye al conocimiento del pasado a través del abordaje de su biografía, en la cual confluyen significaciones en relación a sus usos, sentidos, apropiaciones, condensaciones, dinámicas y relaciones personales, familiares e institucionales. El objeto incrementa la posibilidad de acercarnos al pasado, facilitando de manera considerable el trabajo etnográfico. Ningún acontecimiento puede realizarse sin cosas, ninguna historia prescinde de vestigios. Por lo mismo, los procesos biográficos están íntimamente ligados a los objetos, lo cual provee una puerta de entrada para leer el pasado desde estas tramas de materialidad.-

\section{Notas}

\footnotetext{
${ }^{1}$ Este artículo se inscribe en la tesis para obtener el grado de Doctora en Gestión de la Cultura y el Patrimonio titulada: Las Voces de los Objetos: Vestigios, Memorias y Patrimonios en la Gestión y Conmemoración del Pasado. Directores: (PhD) Xavier Roigé Ventura y (PhD) Ricard Vinyes Ribas. Universidad de Barcelona, 2014

${ }^{2}$ Química de la Memoria es una idea original del artista polaco Horst Hoheisel, quien el año 2005 invitó a un equipo interdisciplinario de Buenos Aires a desarrollar un proyecto de memoria basado en talleres de aportación de objetos significativos biográficamente, con el fin de generar una representación colectiva y polifónica del recuerdo de la dictadura argentina (1976-1983). Cada taller o grupo de talleres culminaba con una exposición o instalación formada por los objetos y los textos que consignaban su historia y/o significación. El proyecto fue desarrollado en las ciudades argentinas de Buenos Aires, La Plata y Rosario, y en Montevideo en Uruguay y en Santiago de Chile.

${ }^{3}$ Vestigios es un proyecto de Memoria Abierta de Argentina, consistente en la recolección de objetos (vestigios) de detenidos/as desaparecidos/as y sobrevivientes de la dictadura argentina, los cuales son relatados por sus dueños y dispuestos en una plataforma digital de acceso público. Busca expresar, a partir de la historia y puesta en valor de los objetos, de la profundidad de la experiencia personal y colectiva del terrorismo de Estado y sus consecuencias.
}

\footnotetext{
${ }^{4}$ Arqueología de la Ausencia es una obra de archivo de la artista visual chilena Verónica Troncoso. Consiste en la búsqueda de objetos, cartas y fotografías de D.D, los que conservados por sus familiares, constituyen aquello que quedó de ellos y que permite aproximarnos a su vida. Para ello, se construyó un archivo visual y sonoro de acceso público, donde se accede a la biografía material de los sujetos.

${ }^{5}$ El objetivo central de la investigación refiere al contexto chileno desde 1990 al presente. Los proyectos argentinos Vestigios y Química de la Memoria, han sido considerados como referentes teóricos y prácticos complementarios para hacer frente a la carencia en Chile de proyectos de memoria basados en objetos.

${ }^{6}$ En la fenomenología de la memoria, el término aristotélico de mnéme refiere a la presencia en la mente de aquello que ya sucedió y que ya no está, recuerdos o imágenes de recuerdos pasados, por ende expresión de lo ausente. Luego, encontramos la práctica de hacer memoria llamada anamnesis, rememoración y/o reminiscencia; traer lo ausente, aquello que ya pasó, al presente.

${ }^{7}$ Tras múltiples definiciones e interpretaciones del fenómeno abiertas desde la investigación histórica y ciencias sociales (Halbwachs, Nora, Le Goff y Ricoeur) -donde ha primado fuertemente el intento por diferenciar memoria e historia-, obtenemos hoy como
} 
epílogo interesantes propuestas orientadas a entender la memoria como un espacio de producción, activo antes que pasivo, siempre en movimiento antes que estático. Se trata de entender la memoria en el sentido sugerido por Vázquez, como una práctica social de recuerdo, un fenómeno intersubjetivo compuesto por afirmaciones, reconocimientos, códigos y significados desplegados en escenarios individuales y colectivos.

${ }^{8}$ La conmemoración refiere a una forma específica de hacer memoria. Constituye una celebración de personajes, hechos o fechas específicas. Consiste en el conjunto de actos declarativos y políticos de recordar y representar a personas y acontecimientos puntuales, los cuales pueden transformar los significados del pasado y movilizar el presente (Hite, 2013). La actividad conmemorativa constituiría una parte específica y distintiva de las prácticas mnemónicas, la cual apuntaría a sujetos, fechas y acontecimientos específicos y se realizaría en actos, ritualidades, ceremonias o lugares desarrollados para tales fines. El pasado deja huellas, recuerdos, ruinas y marcas, no obstante, para construir esa memoria los recuerdos deben ser re-evocados, representados y ubicados en un marco dador de sentido. "Se busca que lo importante no pase desapercibido, que los que no saben se enteren, que reconozcan un día o un lugar y participen de un evento que merece notable distinción del resto de las experiencias grupales" (Tovar \& Albarrán, 2008:2) Así, la conmemoración se distinguiría de la memoria por cuanto recuerda sujetos, hitos y episodios concretos, a través de actos o ceremonias más o menos organizadas que se caracterizan por ser actos de transmisión y transferencia. De esta forma, un acto conmemorativo constituye concretamente una ceremonia para recordar fechas, aniversarios o actores históricos, y a su vez constituye ocasiones públicas, espacios abiertos "para expresar y actuar los diversos sentidos que se le otorga al pasado, reforzando algunos, ampliando y cambiando otros" (Jelin, 2002:245). Tomamos las ideas de la antropóloga Alicia del Campo, quien elaboró el concepto de teatralidad social para explorar los modos en que diversos grupos productores de discursos culturales "son capaces de articular propuestas de identidad nacional y de memoria histórica a través de la puesta en escena de una variedad de espectacularidades que se apropian estratégicamente de elementos del imaginario cultural para reelaborarlos en función de sus propios intereses y poder así modelar la sensibilidad social de una colectividad" (Del Campo, 2004:22). Las conmemoraciones en cuestión, incluirían precisamente estas teatralidades expresadas por Alicia del Campo: "Utilizaré aquí la teatralidad en su sentido más amplio: el de teatralidad social. La multiplicidad de formas en que se expresa la teatralidad social cubre, desde esta mirada, un amplio espectro que va desde las ritualizaciones estandarizadas que van a formar parte de los movimientos de protesta, hasta los modos individuales de encarnación de aquellos ejes simbólicos centrales" (Op.cit.:39).

${ }^{9}$ En el campo antropológico, los objetos también reportan importancia al ser considerados partes constituyentes de nuestra cultura material, preocupación tan central de la antropología. Analizar objetos y sus tecnologías ha sido trascendente para estudiar esquemas de evolución social, difusión, aculturación y cambios. Así, la antropología ha considerado los objetos como elementos activamente implicados en la formación de la cultura y sus componentes: sistemas sociales y sistemas cognitivos. Particularmente, para la antropología simbólica "los objetos son una especie de textos a través de los cuales son construidos los significados y que mediante las relaciones de poder son modificados o construidos" (González, 2010: 67) Aquí, la cultura material constituiría un texto que condensa signos y significados que por medio de su conocimiento e interpretación revelan al observador sistemas simbólicos de significados del mundo social. "El uso y producción de objetos es simultáneamente el uso y reproducción del sistema del que forman parte" (Tirado, 2001: 195).

${ }_{10} \mathrm{Sin}$ duda que una obra de referencia para los estudios antropológicos de cultura material es La vida social de las cosas de Arjun Appadurai (1991), la cual analiza la circulación de las mercancías en la vida social a objeto de emprender una revitalizada antropología de las cosas. Si bien el material primordial de este pensamiento son los objetos-mercancías, las directrices planteadas a lo largo del texto han servido para comprender el uso y significados de las cosas/objetos irrestrictas al campo de las mercancías. Para Appadurai el principal valor de las mercancías en la vida social se define por su posibilidad de ser intercambiado. Esta premisa prepara el camino para analizar la potencialidad de los objetos para convertirse en mercancías siguiendo el proceso completo de producción, intercambio, distribución y consumo. "Debemos seguir a las cosas mismas, ya que sus significados están inscritos en sus formas, usos y trayectorias. Es solo mediante el análisis de estas trayectorias que podemos interpretar las transacciones y cálculos humanos que animan las cosas" (Appadurai, 1991:19) En este contexto, el autor sostiene que las mercancías, como las personas, tienen una vida social, tal como también señala en la misma obra Kopytoff, las mercancías "pueden concebirse provechosamente como si tuviesen historias vitales" (Kopytoff, 1991:33), es decir, una biografía cultural. Por su parte, Alfred Gell (1998) en su obra Art and Agency, sugirió un giro etnográfico al considerar que la experiencia del arte se relaciona con una forma especial de atribución de agencia a los objetos y las imágenes. Con el concepto de agencia del objeto, Gell busca dar cuenta sobre los modos en que los artefactos pueden afectar a las personas en diversos sentidos: movilizan respuestas emocionales, generan o reactivan ideas y provocan variedad de acciones y procesos sociales. Para Gell, los objetos, en un sentido similar a las ideas de Appadurai y Kopytoff, participan de marcos específicos de interacción en los cuales constituyen medios a través de los cuales se manifiestan y realizan acciones. Gell constituye una vía de acceso para comprender la propuesta del actor-red de Bruno Latour (2005), quien supera las ideas arriba encadenadas al proponer que los objetos serían actantes con capacidad de agencia, capaces de modificar con su incidencia un estado de cosas, es decir, asumir la categoría de actor o participante en el curso de la acción, abriéndole la posibilidad de incidir en la creación de lo social. La idea central es que los objetos constituyen fuerzas sociales que se entretejen con otras en la acción dando origen a un reensamblado con distintos tipos de actores.

${ }^{11}$ En el caso de los museos, también es posible identificar este poder sustituyente. Aquí el objeto estaría en representación de algo 
inmaterial que solo es posible objetivizar a través del círculo mágico que brindan estos objetos fetichizados, los cuales seleccionados entre muchos vestigios dejan de ser lo que eran en sí mismos, comenzando a ser en sustitución de otra cosa desaparecida en el sentido de la semiosis sustituyente. De esta forma, el objeto nos conduce automáticamente a la ausencia de aquello que es inalcanzable por su imposibilidad de volver a ser alguna vez, porque ya fue, porque ya existió. Aquello ausente, que fue y que ya no está, puede ser reemplazado por objetos que siempre estarán remitiendo a algo distinto de sí mismos, prestando utilidad a algo distinto de su esencia y que le trasciende.

${ }^{12}$ Con el término narrativas de la dictadura, se hace referencia a la construcción narrativa-discursiva elaborada por las instituciones

\section{Referencias bibliográficas}

Appadurai, A. (ed.) (1991). La vida social de las cosas. Perspectiva cultural de las mercancías. México: Grijalbo.

Baudrillard, J. (2010). El sistema de los objetos. México: Siglo XXI.

Da Silva, L. (2006). "Las marcas materiales del recuerdo". Disponible en: http://www.me.gov.ar/monitor/nro6/dossier8.html Fecha de consulta: 15 de julio de 2013.

De Certeau, M. (1999). La invención de lo cotidiano. Artes de hacer. México: Cultura Libre.

Del Campo, A. (2004). Teatralidades de la memoria. Rituales de la reconciliación en el Chile de la transición. Santiago: Mosquito Ediciones.

Gell, A. (1998). Art and Agency. An Anthropological Theory. Oxford: Oxford University Press.

Guerrero, P. (2002). Guía etnográfica. Sistematización de datos sobre la diversidad y la diferencia de las culturas. Quito: Ediciones Abya-Yala.

Halbwachs, M. (1990). "Espacio y memoria colectiva". Estudios sobre las Culturas Contemporáneas, № 9.

Hite, K. (2013). Política y arte de la conmemoración. Memoriales en América Latina y España. Santiago: Mandrágora.

Jelin, E. (2002). "Los sentidos de la conmemoración". En Jelin, E. \& Candina, A. (comps). Las conmemoraciones: las disputas en las fechas "in-felices". Buenos Aires: Siglo XXI.

Latour, B. (2008). Reensamblar lo social. Una introducción a la en relación al pasado, la cual van forjando una visión y verdad respecto a los hechos y su interpretación. Las narrativas de la dictadura van tomando forma en los discursos oficiales, en los guiones museográficos, en las propuestas reparatorias y en los recursos textuales de los memoriales, entre otros. Tras una atenta lectura de las tramas narrativas tejidas, se va develando una noción ideológica de éticas y valores que sustentan el discurso público de la memoria, el cual se espera, sea aceptado por un amplio grupo de la sociedad.

${ }^{13}$ Las políticas de reparación iniciadas en 1990, están basadas en esta noción traumatológica de la reparación, lo cual ha llevado a levantar programas y proyectos conducentes a restablecer la dignidad de quienes sufrieron violación de sus derechos fundamentales.

teoría del actor-red. Buenos Aires: Manantial.

Montero, C. (2012). Vulnerabilidad, reconocimiento y reparación. Praxis cristiana y plenitud humana. Santiago: Universidad Alberto Hurtado.

Nora, P. (2009). Los lugares de la memoria. Santiago: LOM.

Osorio, J. \& Rubio, G. (2006). El deseo y la memoria. Escritura e historia. Santiago: Gráfica Andes.

Radley, A. (1990). "Artefactos, memoria y sentido del pasado". En David, M. \& Derek, E. (comps.). Memoria compartida. La naturaleza social del recuerdo y del olvido. Barcelona: Paidós.

Tirado, F. (2001). Los objetos y el acontecimiento: teoría de la socialidad mínima. (Tesis Doctoral). Departamento de Psicología de la Salud y de Psicología Social, Facultad de Psicología, Universidad Autónoma de Barcelona.

Tovar, A. \& Albarrán, V. (2008). "Las prácticas conmemorativas: el pasado familiar o lo familiar del pasado". Boletín Electrónico de Investigación de la Asociación Oaxaqueña de Psicología, № 1.

Vázquez, F. (2001). La memoria como acción social: relaciones, significados e imaginarios. Barcelona: Paidós. 